\title{
Diagnóstico de Manguezais Periurbanos após 20 anos de impactos antrópicos
}

\author{
Diagnosis of Periurban Mangroves after 20 years of anthropic impacts \\ Diagnóstico de Manglares Periurbanos tras 20 años de impactos antropicos
}

Recebido: 27/11/2020 | Revisado: 01/01/2021 | Aceito: 09/01/2021 | Publicado: 09/01/2021

\author{
Katia Domingues Blotta \\ ORCID: https://orcid.org/0000-0003-1116-8581 \\ Universidade Santa Cecília, Brasil \\ E-mail: katiablotta@unisanta.br \\ Luciana Lopes Guimarães \\ ORCID: https://orcid.org/0000-0002-7230-9571 \\ Universidade Santa Cecília, Brasil \\ E-mail: lucianafarm@unisanta.br \\ Eliane Marta Quinoñes Braz \\ ORCID: https://orcid.org/0000-0002-6907-9832 \\ Universidade Metropolitana de Santos, Brasil \\ E-mail: elianemqbraz@hotmail.com \\ Mara Angelina Galvão Magenta \\ ORCID: https://orcid.org/0000-0003-0194-6386 \\ Universidade Santa Cecília, Brasil \\ E-mail: maramagenta@unisanta.br \\ Renan Braga Ribeiro \\ ORCID: https://orcid.org/0000-0001-9223-3394 \\ Universidade Santa Cecília, Brasil \\ Universidade de São Paulo, Brasil \\ E-mail: renanribeiro@unisanta.br \\ Fábio Giordano \\ ORCID: https://orcid.org/0000-0002-6384-9867 \\ Universidade Santa Cecília, Brasil \\ E-mail: giordano@unisanta.br
}

\begin{abstract}
Resumo
O crescimento das zonas urbanas ao longo das últimas décadas vem interferindo na dinâmica dos manguezais, prejudicando a prestação de serviços ecossistêmicos. O objetivo do presente estudo foi verificar o perfil da distribuição das espécies vegetais, alterações na estrutura do solo e nos parâmetros que atestam a qualidade da água em manguezais periurbanos às margens do Rio Itanhaém, no município de Itanhaém (São Paulo, Brasil). Os resultados obtidos neste estudo, realizado entre os anos de 2017 e 2019, foram confrontados com estudos conduzidos entre os anos de 1996 e 1998, refletindo numa comparação de quase duas décadas de incremento na urbanização, em face do aumento populacional de $31 \%$ entre 1997 e 2017. As análises sugeriram alteração da composição de espécies vegetais das parcelas estudadas, especialmente naquelas mais próximas ao Rio Itanhaém. Os resultados das análises de sedimento demonstraram incremento de matéria orgânica no solo das estações de coleta e as análises da qualidade das águas nos diferentes pontos de coleta mostraram resultados em desacordo com os parâmetros estabelecidos pelas Resoluções CONAMA 357/05 e 274/00. A partir dos resultados obtidos, foi possível verificar que a velocidade com que vem se processando a expansão e especulação urbana nas cidades litorâneas, tem levado a uma degradação do ecossistema manguezal e entende-se que seja da maior importância haver o monitoramento da vegetação litorânea.
\end{abstract}

Palavras-chave: Conservação de manguezais; Despejo de esgoto; Estuário; Rio Itanhaém.

\begin{abstract}
The growth of urban areas over the past decades has interfered with the dynamics of mangrove ecosystems, hampering the provision of ecosystem services. The aim of the present study was to verify the profile of the distribution of plant species, changes in soil structure and parameters that attest to water quality in periurban mangrove ecosystem by the Itanhaém River, in the municipality of Itanhaém (São Paulo, Brazil). The results obtained in this study, carried out between the years 2017 and 2019, were then confronted with studies conducted between the years 1996 and 1998, reflecting a comparison of almost two decades of increase in urbanization, due to the population increase of $31 \%$ between 1997 and 2017. The analysis suggested that there was a change in the composition of plant species in the plots studied, especially in those closer to the Itanhaém River. The results of the sediment analysis showed an increase of organic matter in the soil of the collection stations. The analysis of the water quality in the different collection points showed results in disagreement with the parameters established by the Brazilian Resolutions CONAMA 357/05 and 274/00. From the results obtained, it was possible to verify that the speed with
\end{abstract}


which urban expansion and speculation in coastal cities has been taking place and has led to a degradation of the mangrove ecosystem, emphasizing the importance of monitoring coastal vegetation.

Keywords: Mangrove conservation; Sewage dump; Estuary; Itanhaém River.

\section{Resumen}

El crecimiento de las áreas urbanas durante las últimas décadas ha interferindo con la dinámica de los manglares, lo que ha obstaculizado la provisión de servicios ecosistémicos. El objetivo del presente estudio fue verificar el perfil de distribución de especies vegetales, cambios en la estructura del suelo y parámetros que dan fe de la calidad del agua en manglares periurbanos a orillas del río Itanhaém, en el municipio de Itanhaém (São Paulo, Brasil). Los resultados obtenidos en este estudio, realizado entre los años 2017 y 2019, fueron comparados con estudios realizados entre los años 1996 y 1998, reflejando una comparación de casi dos decadas de aumento de la urbanización, debido al aumento poblacional del 31\% entre 1997 y 2017. Los análisis sugieren que hubo un cambio en la composición de especies vegetales en las parcelas estudiadas, especialmente en las más cercanas al río Itanhaém. Los resultados del análisis de sedimentos mostraron un aumento de materia orgánica en el suelo de las estaciones de recolección y el análisis de la calidad del agua en los diferentes puntos de recolección arrojó resultados en desacuerdo con los parámetros establecidos por las Resoluciones brasileñas CONAMA 357/05 y 274/00. A partir de los resultados obtenidos, se pudo constatar que la rapidez con la que se viene produciendo la expansión urbana y la especulación en las ciudades costeras ha llevado a una degradación del ecosistema de manglar y se entiende que el monitoreo de la vegetación costera es de suma importancia.

Palabras clave: Conservación de manglares; Vertedero de aguas residuales; Estuario; Río Itanhaém.

\section{Introdução}

Manguezais são importantes ecossistemas costeiros biológica e troficamente ativos, favorecendo produtores primários e ampla gama de comunidades micro e macrobentônicas (Schaeffer-Novelli, 1995; Schaeffer-Novelli et al., 2000). Esses ambientes capturam e armazenam carbono de forma eficiente e, além disso, possuem alta capacidade de resiliência, podendo representar um papel importante como barreira física em face do atual aumento do nível do mar, já que suas raízes atuam na estabilização do solo, diminuindo a frequência de inundações (Alongi, 2008; Schaeffer-Novelli et al., 2016).

Lugo \& Snedaker (1974) classificaram manguezais em seis tipos fisiográficos: franja, bacia, ribeirinho e ilhote. Cada uma dessas categorias é influenciada por conjuntos de assinaturas de energia semelhantes, então que dentro de cada tipo de floresta níveis semelhantes de desenvolvimento são alcançados. Cintrón et al. (1985) sugeriram que esta classificação poderia ser reduzida para três grandes tipos (Franja, Ribeirinho e Bacia).

O constante crescimento das zonas urbanas ao longo das últimas décadas está entre as principais causas da perda de áreas de manguezal, sobretudo em países em desenvolvimento, e vem interferindo na dinâmica desses locais e prejudicando a prestação de serviços ecossistêmicos pelos manguezais (Blasco et al., 1996; Alongi, 2015; Ellison, 2014; Bernardino et al., 2020, Moschetto et al., 2020).

Por estarem em estuários e baias protegidas, os manguezais do tipo franja são propensos à maior ocupação humana. Esses ambientes estão sujeitos a variações de salinidade e condições nutricionais e a padronização da vegetação é, em condições normais, impulsionada pela enchente das marés (Schaeffer-Novelli et al., 2000; 2016). Esses padrões, no entanto, podem ser alterados pelo despejo de efluentes domésticos, resultando em mudanças nas condições do solo e da água e essas alterações podem gerar instabilidade em muitas funções do ecossistema, em condições climáticas presentes e futuras (Lovelock et al., 2009).

No município de Itanhaém-SP foram detectadas, há cerca de 20 anos, alterações na estrutura sedimentar dos manguezais de franja localizados às margens do Rio Itanhaém (Quiñones, 2000; Quiñones \& Perez Filho, 2001). Em face do aumento do despejo de efluentes nos últimos anos, o presente estudo teve como objetivo verificar se houveram alterações na distribuição das espécies vegetais e na estrutura do solo desses locais, bem como nos parâmetros que atestam a qualidade da água na porção estuarina do Rio Itanhaém entre as duas últimas décadas. 


\section{Metodologia}

\section{1 Áreas de estudo e coleta de amostras}

Essa pesquisa foi feita em manguezais periurbanos às margens do Rio Itanhaém, no município de Itanhaém, SP, Brasil $\left(24,181413^{\circ} \mathrm{S}\right.$ e $\left.46.796321^{\circ} \mathrm{W}\right)$. O clima é do tipo Af, pelo sistema de Köppen. A temperatura média é de $22,9^{\circ}$ e a pluviosidade média anual é de 2120mm (Climate-data, 2020). Considerando o ano de 2018 como referência, o município tem uma população de 100.496 habitantes, sendo 44,6\% dessa população atendida com esgotamento sanitário (Brasil, 2019).

A bacia hidrográfica do Rio Itanhaém está localizada no litoral sul do Estado de São Paulo, com sua maior parte dentro do município de mesmo nome. Essa bacia tem uma área de aproximadamente 900 km² (CBH-BS, 2016). A porção superior da bacia está localizada em parte da Serra do Mar, em altitudes entre 600 e 800 m, com vegetação de Mata Atlântica (Floresta Ombrófila) bem preservada; na porção média, em altitudes entre 5 e $20 \mathrm{~m}$, é encontrada mata de restinga com preservação moderada, enquanto a porção inferior da bacia (região estuarina) é caracterizada por altitudes entre 0 e $5 \mathrm{~m}$ e vegetação de manguezal (Souza-Pereira e Camargo, 2004). Essa porção inferior da bacia está submetida a diversos impactos antrópicos, dentre os quais o recebimento de esgoto orgânico sem tratamento, pois está envolvida pela área urbana (Pereira, 2002).

Na planície costeira a precipitação média anual é de 1.000 a 2.000 mm, durante o verão a precipitação média mensal é de 250,6 mm e no inverno 56,1 mm (Camargo et al., 1997). Segundo o CBH-BS (2016) a precipitação média ponderada anual é de $2.078 \mathrm{~mm}$ para toda a bacia. A vazão média do Rio Itanhaém varia entre 32 e $50 \mathrm{~m}^{3} \mathrm{~s}^{-1}$ com descarga de sedimentos constituída de argila e areia fina (CBH-BS, 2016; de Araújo \& Alfredini, 2003), sendo as maiores vazões no verão e menores no inverno, seguindo a precipitação. A maré na região costeira, assim como em toda a costa do Estado de São Paulo é mista com predominância semidiurna, com maiores variações de 1,5 m (de Araújo \& Alfredini, 2003). Segundo Harari e Camargo (2003) as componentes harmônicas de maré com maiores amplitudes são a M2 e S2 com 0,36 m e 0,21 m.

Na região estuarina, o Rio Itanhaém é sinuoso e com regime fluvial de baixa energia (de Araújo \& Alfredini, 2003), e sofre grande influência de águas marinhas, apresentando amplas variações de salinidade, de pH, e de oxigênio dissolvido em uma escala horária/diária devido às ações das marés, e em escala sazonal devido à pluviosidade (Camargo et al., 1996).

No presente estudo, foram investigadas as condições de preservação de manguezais periurbanos existentes ao longo do rio Itanhaém e das águas em seu entorno. Os resultados obtidos foram confrontados com os estudos conduzidos por Quiñones (2000) e Quiñones \& Perez Filho (2001) entre os anos de 1996 e 1998, refletindo numa comparação de quase duas décadas de incremento na urbanização em face do aumento populacional de 31\% entre 1997 e 2017.

O estudo da vegetação e do solo (2017) foi feito em três estações de coleta (E1, E2, E3). Adicionalmente, foram coletadas amostras de água para análises físico-químicas e microbiológicas nos mesmos 10 pontos amostrados pelos autores (op. cit.) (pontos 1 a 10). Foram acrescidos ao presente estudo dois pontos próximos a saída dos efluentes de duas Estações de Tratamento de Esgoto (ETE) no Rio Itanhaém (pontos 11 e 12), totalizando 12 pontos amostrados no dia 22 de janeiro de 2019 (Figura 1). Cabe ressaltar que nos trabalhos de comparação (Quiñones, 2000; Quiñones \& Perez Filho; 2001), havia despejo de esgoto apenas nas estações 1 e 2 e a estação 3 serviu como área de controle para o estudo conduzido entre 1996 e 1998.

Atualmente, os três locais (estações) recebem esgoto, pois existe uma ETE a montante da estação 3 e outra à jusante da estação 2. Além disso, nas estações 1 e 2 foram identificados efluentes domésticos também carreados in natura pelo Rio do Poço, que tem 14 km de extensão e despejo de esgoto ao longo de cerca de 1,3 Km, e pelo Ribeirão Campininha, com pouco mais de $2 \mathrm{Km}$ e despejo de esgoto ao longo de $1,8 \mathrm{Km}$ de seu comprimento. 
Figura 1. Local de estudo no município de Itanhaém, SP, Brasil, com destaque para as estações de análise da vegetação (E1 a E3) e pontos de coleta das amostras de água (1 a 12).

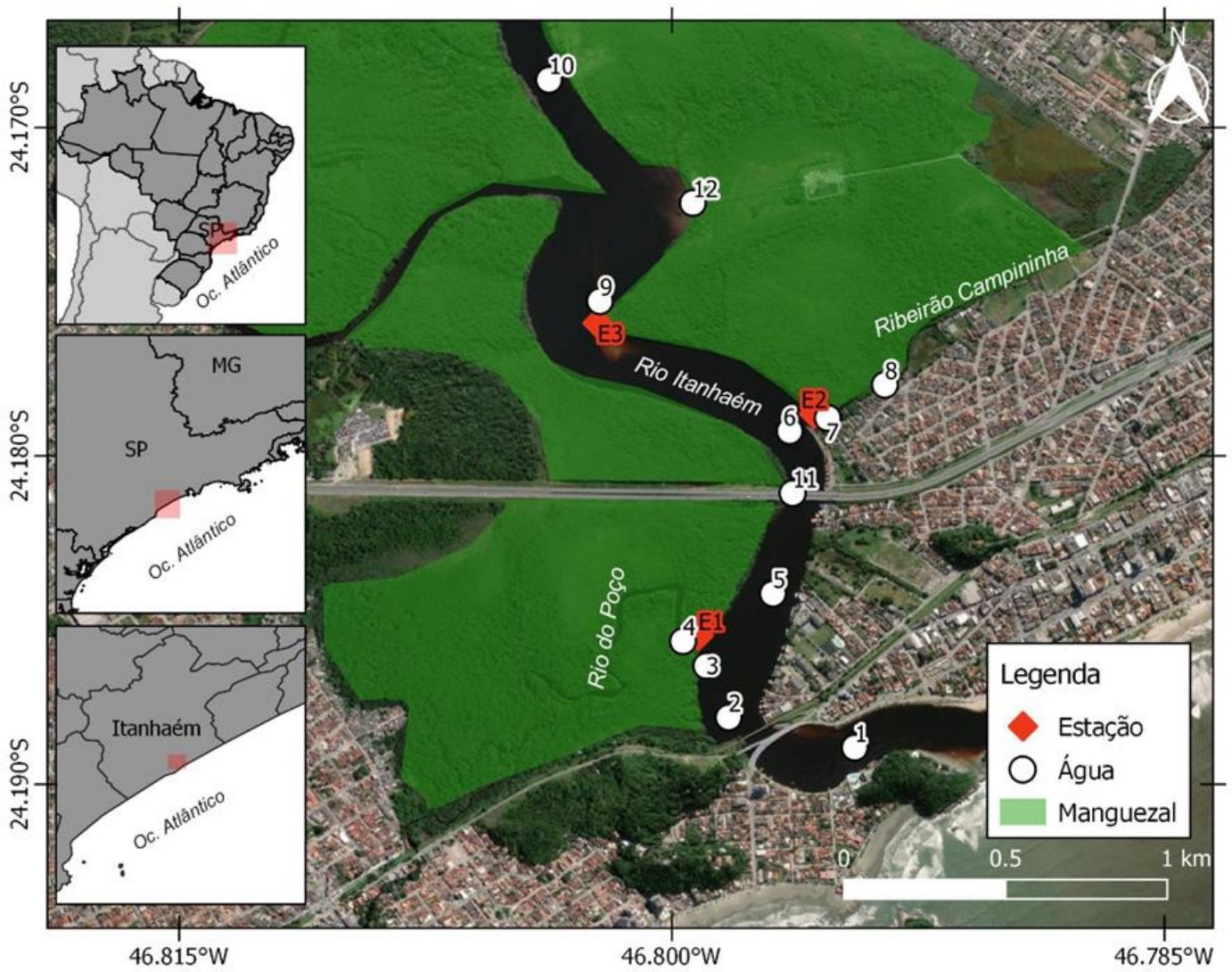

Fonte: Autores (2020).

Os dados fitossociológicos foram obtidos em julho de 2017, durante a maré baixa, em nove parcelas de 5m x 10m, com a maior dimensão paralela ao Rio Itanhaém, sendo três por estação de coleta. A amostragem incluiu todos os indivíduos arbóreos com perímetro à altura do peito (PAP, convencionado a 1,30 m acima do substrato) $\geq 10 \mathrm{~cm}$. As plântulas (plantas com o primeiro par de folhas) foram quantificadas em todas as Estações.

Para determinar a granulometria aproximada e a matéria orgânica no solo nas parcelas mais próximas ao Rio Itanhaém, foi coletada uma amostra em cada estação de coleta, a $20 \mathrm{~cm}$ de profundidade, nos seguintes pontos: 1.1 $\left(24,178601^{\circ} \mathrm{S}\right.$ e $\left.46,795260^{\circ} \mathrm{W}\right), 2.1\left(24,185425^{\circ} \mathrm{S}\right.$ e $\left.46,798503^{\circ} \mathrm{W}\right), 3.1\left(24,175607^{\circ} \mathrm{S}\right.$ e $\left.46,801883^{\circ} \mathrm{W}\right)$. As amostras foram ensacadas, etiquetadas e transportadas ao Laboratório de Mecânica de Solos da Universidade Santa Cecília.

As amostras de água foram coletadas em 12 pontos (Tabela 1) durante a maré vazante, visando obter maior influência das águas fluviais e dos efluentes lançados. Para as análises físico-químicas foi realizada apenas uma amostragem por local, a $15 \mathrm{~cm}$ de profundidade, e armazenada em garrafa plástica. Para as análises microbiológicas foram coletadas três amostras por local, em profundidade de 15 a $20 \mathrm{~cm}$, contra a correnteza, armazenadas em garrafa de vidro âmbar previamente esterilizada. A temperatura do ar e a das amostras de água foi obtida in situ com termômetro infravermelho. 
Tabela 1. Pontos de coleta de amostras de água no Estuário de Itanhaém-SP, para as análises físico-químicas e microbiológicas.

\begin{tabular}{cccc}
\hline Local de coleta & Pontos de coleta & Longitude $\left(^{\circ}\right)$ & Latitude $\left(^{\circ}\right)$ \\
\hline Rio Itanhaém & 1 & $-46,79443$ & $-24,18889$ \\
Rio Itanhaém & 2 & $-46,79827$ & $-24,18797$ \\
Rio do Poço & 3 & $-46,79895$ & $-24,1864$ \\
Rio do Poço & 4 & $-46,79966$ & $-24,18565$ \\
Rio Itanhaém & 5 & $-46,79692$ & $-24,1842$ \\
Rio Itanhaém & 6 & $-46,79641$ & $-24,17925$ \\
Ribeirão Campininha & 7 & $-46,79525$ & $-24,17885$ \\
Ribeirão Campininha & 8 & $-46,79351$ & $-24,17784$ \\
Rio Itanhaém & 9 & $-46,80219$ & $-24,17529$ \\
Rio Itanhaém & 10 & $-46,80374$ & $-24,16855$ \\
ETE Guarapiranga & 11 & $-46,79632$ & $-24,18114$ \\
ETE Anchieta & 12 & $-46,79936$ & $-24,1723$ \\
\hline
\end{tabular}

Fonte: Autores.

\subsection{Análise de dados}

\subsubsection{Vegetação}

Foram calculados densidade, dominância e frequência relativas, e índice de valor de importância (IVI) para cada espécie arbórea, segundo Mueller-Dombois \& Ellenberg (1974).

\subsubsection{Sedimento}

As amostras de solo foram transferidas para placas de Petri e pesadas imediatamente, obtendo-se o peso úmido (PU), descontando-se o peso das placas. As mesmas foram secas a $60^{\circ} \mathrm{C}$ em estufas sem circulação de ar, até a estabilização do peso, ocorrida após 48 horas (peso seco). Posteriormente, foi feita a separação granulométrica (tamisação), em 4 peneiras com as seguintes malhas: $>0,300 \mathrm{~mm},>0,140 \mathrm{~mm},>0,075 \mathrm{~mm}$ e $<0,075 \mathrm{~mm}$. A classificação da granulometria foi baseada nos critérios definidos pelo Sistema Unificado de Classificação dos Solos (SUCS) (Casagrande, 1948).

Uma alíquota de $10 \%$ das amostras foi transferida para cadinhos de cerâmica e levada à mufla a aproximadamente $600^{\circ} \mathrm{C}$, por 40 minutos, para eliminação de resíduos orgânicos. A porcentagem de matéria orgânica foi determinada em razão da perda de massa do resíduo incinerado, considerando-se o material perdido pela queima.

\subsection{3 Águas}

Para cada amostra de água foram determinados: temperatura, aferida in situ com termômetro infravermelho (Infrared, modelo DT-500); salinidade com o refratômetro de salinidade (ATC®); pH, com pHmetro (HANNA®, modelo HI98103); oxigênio dissolvido (OD), com uso de oxímetro (Digimed®, modelo DM-4P); cor aparente pelo uso do colorímetro (PoliControl®, modelo NQ 200); Sólidos Totais Dissolvidos (TDS) na água em ppm (partes por milhão) foi determinada pelo equipamento TDS\&EC.

Os resultados para salinidade foram expressos em \%o (permilagem); para OD foram expressos em mg.L $\mathrm{L}^{-1}$ e para cor 
aparente foram expressos em unidades de cor ( $\mathrm{uH}$ - unidade Hazen). A turbidez também foi determinada nas amostras com uso de turbidímetro (Policontrol®, modelo AP2000). Os resultados foram expressos em Unidades Nefelométricas de Turbidez (UNT) (APHA, 2017).

As análises microbiológicas foram realizadas através da determinação de Escherichia coli para cada amostra de água. O método adotado foi a técnica da filtração em membranas (APHA, 2017). As amostras de água foram homogeneizadas e filtradas em membrana de celulose estéril quadriculada com porosidade de 0,45 $\mu \mathrm{m}$. Depois, com auxílio de uma pinça estéril, as membranas foram depositadas em placas de Petri contendo o meio de cultura Ágar Biochrome Coliformes (Biolog). Após incubação das placas a $35 \pm 0,5^{\circ} \mathrm{C}$ por 24 horas, foram efetuadas as contagens colônias típicas de E. coli. Os resultados foram expressos como (UFC/100ml) e realizados em triplicata. Os valores de referência para E. coli em águas são definidos pela resolução CONAMA n ${ }^{\circ}$ 274, de 29 de novembro de 2000 (BRASIL, 2000), como um dos indicadores de contaminação fecal e pelo órgão ambiental do estado de São Paulo (CETESB, 2012) na avaliação da qualidade dos corpos de água.

\section{Resultados e Discussão}

\subsection{Vegetação}

Três das quatro espécies arbóreas ocorrentes no sudeste brasileiro foram encontradas nas áreas de estudo: Rhizophora mangle L., Avicennia schaueriana Stapf \& Leechm. ex Moldenke e Laguncularia racemosa (L.) C. F. Gaertn, totalizando 288 árvores adultas e 463 plântulas.

A Estação 1 apresentou o maior número de árvores (154), seguido pela Estação 3 (110 indivíduos); nessas estações, a espécie com maior número de indivíduos foi A. schaueriana. Na Estação 2, localizada próximo à descarga do Ribeirão Campininha no Rio Itanhaém, foram contabilizadas apenas 24 árvores, com predomínio de R. mangle. A maior quantidade de plântulas foi encontrada na Estação 3 (361), seguido pela Estação 1 (63); na Estação 2, foram encontradas 39 plântulas (Tabela 2).

Tabela 2. Quantidade de árvores adultas por espécie encontradas em 2017 nos manguezais de franja periurbanos do Rio Itanhaém e comparação do número de plântulas existentes em 1997 e 2017 nas mesmas três estações de coleta.

\begin{tabular}{|c|c|c|c|c|c|}
\hline $\begin{array}{l}\text { Estação } \\
\text { de coleta }\end{array}$ & Avicennia schaueriana & Laguncularia racemosa & Rhizophora mangle & $\begin{array}{c}\text { 17/08/1997 } \\
\text { Plântulas } \\
\text { (Quiñones, 2000) }\end{array}$ & $\begin{array}{c}\text { 26/07/2017 } \\
\text { Plântulas } \\
\text { (este estudo) }\end{array}$ \\
\hline 1.1 & 46 & 19 & 3 & 17 & 31 \\
\hline 1.2 & 15 & 18 & 6 & 20 & 16 \\
\hline 1.3 & 18 & 19 & 10 & 21 & 16 \\
\hline 2.1 & 2 & 6 & 7 & 18 & 21 \\
\hline 2.2 & 0 & 1 & 4 & 17 & 12 \\
\hline 2.3 & 1 & 1 & 2 & 13 & 6 \\
\hline 3.1 & 18 & 0 & 13 & 10 & 138 \\
\hline 3.2 & 15 & 5 & 22 & 12 & 109 \\
\hline 3.3 & 21 & 0 & 16 & 12 & 114 \\
\hline
\end{tabular}


A. schaueriana foi a espécie de maior índice de valor de importância (IVI) nas Estações 1 e 3. Na estação 2, $R$. mangle apresentou o IVI mais alto (Tabela 3).

Tabela 3. Densidade relativa (De.R), frequência relativa (Fr.R), dominância relativa (Do.R) e índice de valor de importância (IVI) das três espécies arbóreas encontradas nos manguezais de Itanhaém (SP).

\begin{tabular}{l|ccc|ccc|cccccc}
\hline \multicolumn{1}{c|}{ Espécie } & \multicolumn{3}{|c|}{ Estação 1 } & \multicolumn{5}{|c|}{ Estação 2} & \multicolumn{5}{c}{ Estação 3} \\
\hline & De.R & Fr.R & Do.R & IVI & De.R & Fr.R & Do.R & IVI & De.R & Fr.R & Do.R & IVI \\
& & & & & & & & & & & \\
Avicennia schaueriana & 0,51 & 0,33 & 0,59 & 1,44 & 0,12 & 0,26 & 0,03 & 0,41 & 0,49 & 0,43 & 0,54 & 1,46 \\
Laguncularia racemosa & 0,36 & 0,33 & 0,33 & 1,02 & 0,33 & 0,37 & 0,44 & 1,14 & 0,04 & 0,14 & 0,02 & 0,20 \\
Rhizophora mangle & 0,12 & 0,33 & 0,07 & 0,52 & 0,54 & 0,37 & 0,53 & 1,44 & 0,46 & 0,43 & 0,44 & 1,33 \\
\hline
\end{tabular}

Fonte: Autores.

A constatação feita em 2017, da presença de maior número de indivíduos de A. schaueriana nas parcelas dos pontos 1 e 3 mais próximas ao Rio Itanhaém contrasta com a afirmação de Quiñones (2000) feita com base em observações qualitativas ocorridas entre 1996 e 1998, de que a espécie com maior número de indivíduos nesses locais foi $R$. mangle, o que é tido como corriqueiro em manguezais ribeirinhos, em áreas inundadas pelas marés. (ALMEIDA et al., 2014). Na borda da estação 2, próxima à desembocadura do Ribeirão Campininha, Laguncularia racemosa concorre igualitariamente com R. mangle .

O trabalho de Quiñones (2000), também indicou o predomínio de L. racemosa na porção mais interna de todas as estações de amostragem. Atualmente, essa espécie divide a primeira posição em números de indivíduos com A. schaueriana na subestação 1.3, está representada por apenas um apenas um indivíduo na subestação 2.3 e não ocorreu na porção mais interna do manguezal da estação na subestação 3.3.

Nas parcelas centrais, o predomínio de A. schaueriana encontrado por Quiñones (2000) deu lugar à L. racemosa no Ponto 1 e R. mangle, nos Pontos 2 e 3.

Alterações na hidrodinâmica dos rios e ocorrências naturais (chuvas, ressacas) podem explicar, em parte, mudanças da fisionomia da vegetação ribeirinha, mas o aumento de descarte de esgoto no rio também pode estar desempenhando um papel importante no processo. Yang et al. (2008) demonstraram que algumas espécies de mangue podem ter seu crescimento acelerado na presença de esgoto doméstico, e que isso está associado à sua maior capacidade de remoção de certas substâncias, como carbono e nitrogênio, por exemplo, com consequente incremento de sua capacidade enzimática. Por outro lado, $R$. mangle é a espécie com menor tolerância à elevada concentrações de sal (Olmos \& Silva, 2003); experimentos indicam que quando passam a ocorrer grandes variações salinas em áreas que normalmente possuem baixa salinidade, árvores dessa espécie passam a apresentar sinais de estresse fotoquímico, com alteração da taxa de assimilação de $\mathrm{CO}_{2}$ (Lopes et al. 2019).

A maior quantidade de plântulas (361) foi encontrada na Estação 3, que recebe apenas esgoto tratado; isso representa um aumento de $91 \%$ em relação ao número encontrado por Quiñones (2000). Poderia se cogitar que as características geomorfológicas do Rio Itanhaém favorecem o acúmulo de matéria orgânica de outras origens e propágulos neste local, mas Ricardi-Branco et al. (2009) concluíram que, ao contrário das expectativas, os detritos depositados nesses manguezais têm, em grande parte, origem alóctone, à exceção dos localizados próximos à foz do rio, que podem ter origem mista. Assim, esse aumento pode ser decorrente do despejo da carga de nutrientes enriquecida com fontes de nitrogênio e fósforo proveniente da ETE Anchieta, instalada em 2002. Isso não aconteceu nas Estações que recebem esgoto in natura. 
O número de plântulas aumentou apenas em $8 \%$ na Estação 1, que recebe resíduos lançados em cerca de 9\% da extensão do Rio do Poço e onde havia o maior número de plântulas em 1997, e sofreu redução de $23 \%$ na Estação 2, que também é a menos representativa em número de árvores, e cujo aporte de esgoto procede de uma extensão que representa 80\% do comprimento do Ribeirão Campininha. Convém destacar que, próximo à desembocadura do Ribeirão, existe uma plataforma de pesca ao lado da qual é comum haver várias embarcações pequenas atracadas e pessoas adentrando o manguezal em busca de caranguejo, o que possivelmente causa pisoteio nas plântulas.

\subsection{Solo}

As análises de solo das parcelas mais próximas ao rio indicam a presença de solo arenoso, com grande quantidade de matéria orgânica (Tabela 4). Estudos anteriores indicaram que os solos do manguezal de Itanhaém têm predomínio da classe areia-franca com frações expressivas de areia fina e silte (Lamberti, 1969; Quiñones, 2000, Quiñones \& Perez, 2001).

Tabela 4. Parâmetros sedimentológicos do sedimento superficial coletado em parcelas de manguezal alocadas próximo à franja em cada estação de coleta (E1, E2, E3).

$$
\text { Silte + argila (\%) Areia (\%) Matéria Orgânica (\%) }
$$

Amostras

$$
\leq 0,075 \mathrm{~mm} \quad>0,075 \mathrm{~mm}
$$

\begin{tabular}{llll}
\hline Estação 1 & 4,51 & 95,0 & 48,3 \\
Estação 2 & 17,65 & 82,1 & 48,3 \\
Estação 3 & 8,90 & 91,1 & 33,1 \\
\hline
\end{tabular}

Fonte: Autores.

Foi constatado aumento de matéria orgânica no solo das parcelas mais próximas à margem do Rio Itanhaém, em relação aos resultados de Quiñones (2001), em taxas que variam entre 11,3\% (subestação 1.1) e 14,3\% (subestação 2.1). Parte desse aumento provavelmente se deve à contribuição do despejo de efluentes da ETE, instalada à montante das estações de coleta em setembro de 2002, mas certamente o carreamento de efluentes domésticos pelo Ribeirão Campininha é um fator que merece atenção das autoridades locais.

A eutrofização do solo, sinalizada nesta pesquisa, pode causar alterações na interação entre a bioturbação e a degradação microbiana e potencialmente ocasionar perdas de longo prazo no armazenamento de carbono em áreas urbanas (Bernardino et al. 2020). Tam \& Wong (1996) demonstraram que os solos de manguezais efetivamente retêm também os nutrientes inorgânicos, como nitrato, fosfato e amônia, contidos nos efluentes de esgoto, que a capacidade de retenção varia com o tipo de solo e que a quantidade de matéria orgânica e o "status redox" parecem ser fatores importantes que afetam a capacidade de oferta de nutrientes. Nesse cenário, as condições podem não ser favoráveis à formação e ciclagem de óxidos de Fe que sejam altamente reativos e, portanto, capazes de ligar grandes quantidades de fósforo, o que diminui a capacidade de armazenamento de carbono orgânico (Barcellos et al. 2019).

\subsection{Qualidade da água}

A destinação das águas (contato primário, recreação) e os resultados das análises de salinidade permitem enquadrá-la na Classe 1 de águas salobras da resolução CONAMA 357/2005 (Brasil, 2005). Os resultados das análises da qualidade das águas estão mostrados na Tabela 5. 
Tabela 5. Resultados das análises dos parâmetros físico-químicos das amostras de água coletadas no Estuário de Itanhaém-SP.

\begin{tabular}{|c|c|c|c|c|c|c|c|c|}
\hline $\begin{array}{l}\frac{\pi}{0} \\
\frac{0}{0} \\
0 \\
0 \\
0 \\
0 \\
0 \\
0\end{array}$ & 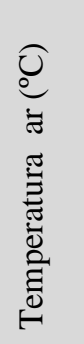 & 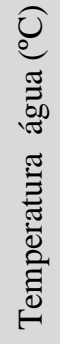 & 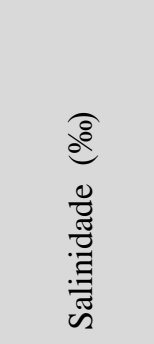 & 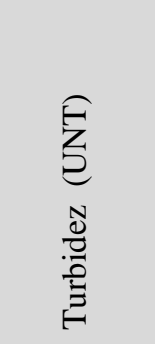 & 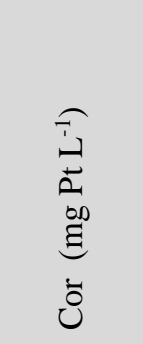 & $\begin{array}{l}\overparen{0} \\
-1 \\
-100 \\
0 \\
0 \\
0 \\
0\end{array}$ & $\begin{array}{l}\hat{E} \\
\hat{\Xi} \\
\tilde{\theta} \\
\hat{\theta}\end{array}$ & $\frac{T}{2}$ \\
\hline 1 & 33 & 31 & 29 & 7,5 & 15 & 7,6 & 4352 & 7,39 \\
\hline 2 & 29 & 30 & 25 & 6,23 & 15 & 7,2 & 4025 & 7,57 \\
\hline 3 & 30 & 30 & 23 & 7,2 & 20 & 7,2 & 3945 & 7,55 \\
\hline 4 & 29 & 29 & 25 & 12,5 & 40 & 6,9 & 3939 & 7,19 \\
\hline 5 & 33 & 29 & 19 & 5,6 & 20 & 8,1 & 3752 & 7,19 \\
\hline 6 & 29 & 29 & 15 & 4,46 & 20 & 8,3 & 3359 & 7,04 \\
\hline 7 & 28 & 29 & 18 & 4,84 & 20 & 8,6 & 3559 & 6,95 \\
\hline 8 & 30 & 29 & 19 & 11,5 & 50 & 6,1 & 3793 & 6,74 \\
\hline 9 & 33 & 29 & 11 & 4,96 & 30 & 7,6 & 2947 & 6,88 \\
\hline 10 & 29 & 29 & 9 & 5,31 & 30 & 7,9 & 2666 & 6,61 \\
\hline 11 & 28 & 29 & 7 & 48,2 & 70 & 1,6 & 2433 & 7,05 \\
\hline 12 & 31 & 29 & 4 & 34,8 & +70 & 1,3 & 1897 & 7,0 \\
\hline $\begin{array}{c}\text { CONAMA } \\
357 / 05^{*}\end{array}$ & -- & -- & $\begin{array}{c}0,5 \% \text { e } \\
30 \%\end{array}$ & $\begin{array}{c}\text { virtualmente } \\
\text { ausentes }\end{array}$ & $\begin{array}{c}\text { virtualmente } \\
\text { ausentes }\end{array}$ & $\begin{array}{c}\text { não inferior } \\
\text { a } 5 \mathrm{mg} / \mathrm{L}\end{array}$ & -- & $6,5-8,5$ \\
\hline
\end{tabular}

*valores de referência para águas salobras de classe 1 segundo a resolução CONAMA 357/05. Fonte: Autores.

A temperatura do ar no momento das coletas (maré vazante) variou de $28^{\circ} \mathrm{C}$ a $33^{\circ} \mathrm{C}$ e a da água oscilou entre $29^{\circ} \mathrm{C} \mathrm{a}$ $31^{\circ} \mathrm{C}$, confirmando a elevada estabilidade térmica temporal típica das águas tropicais. Por outro lado, Quiñones (2000) encontrou valores e variações menores de temperatura da água $\left(21,5^{\circ} \mathrm{C}\right.$ a $22,5^{\circ} \mathrm{C}$, na maré baixa), também tomadas no mês de janeiro.

As medidas de salinidade evidenciam influência da maré em toda a área de estudo, sendo os maiores valores registrados até cerca de $2.200 \mathrm{~m}$ da linha da praia (pontos 1 a 8), com os maiores valores (25\%o a 29\%o) registrados nos locais mais próximos à desembocadura do Rio Itanhaém (1 a 4). Nos lugares que recebem lançamento de esgoto tratado, a salinidade variou de $4 \%$ a $7 \%$.

Dos pontos 1 a 10, os valores de turbidez encontrados variaram de 4,46 a 12,5 NTU, similares aos encontrados por Quiñones (2000), com os maiores números relacionados a locais que recebem esgoto não tratado, na saída dos afluentes aqui considerados (pontos 4 e 8). Cabe ressaltar que a resolução CONAMA 357/05 (Brasil, 2005) estabelece que o parâmetro turbidez deve estar 'virtualmente ausente' para as águas salobras de classe 1. Além de potencialmente afetar a estética dos corpos d'água, a turbidez alta pode promover distúrbios na fauna e na flora, pois interfere na penetração de luz (Derísio, 2013).

Nos pontos 11 e 12, incluídos neste estudo e que recebem esgoto doméstico tratado, os índices de turbidez se elevam de 34,8 a 48,2 NTU, podendo estar relacionados ao lançamento dos efluentes de ETEs.

Os maiores valores para a cor aparente também foram encontrados nos pontos 11 e $12(\geq 70 \mathrm{mg}$ Pt L-1) em relação direta aos altos valores de turbidez. Nos demais pontos, a cor variou de 15 a $50 \mathrm{mg} \mathrm{Pt} \mathrm{L}^{-1}$, com limite superior três vezes menor que os $170 \mathrm{mg} \mathrm{Pt} \mathrm{L}{ }^{-1}$ encontrados nos afluentes que recebiam esgoto da população ribeirinha, em janeiro de 1998. A presença 
da cor na água nem sempre representa risco à saúde, mas a população pode questionar a qualidade da água (CETESB, 2012). Além da influência das atividades antrópicas pelo lançamento de efluentes domésticos e/ou industriais (Von Sperling, 2007), minerais dissolvidos como o ferro e manganês relacionados com a geologia dos solos das margens dos rios também podem provocar o aparecimento de cor na água (CETESB, 2012; Von Sperling, 2007; León, 2005).

Em solos arenosos como os da restinga associados aos manguezais, o processo de podzolização, no qual há a percolação da água no solo, lava cátions e óxidos de ferro da porção superior (Barcelos et al., 2012) e esse material pode se depositar nas águas do rio. Além disso, o aumento das chuvas incrementa o transporte de materiais orgânico e inorgânico drenados nas margens dos rios, o que influencia na cor (Piratoba, 2017). No dia 21 de janeiro de 2019, véspera da coleta de dados, foram registrados 22,5 mm de chuva (o segundo maior índice diário do mês), após três dias sem chuva (DAEE, 2019). As ligninas, taninos, substâncias húmicas e fúlvicas, algas e entre outras, provenientes da decomposição de material orgânico, principalmente de origem vegetal, são também causadoras da cor em águas naturais (León, 2005; CETESB, 2012).

O teor de OD teve variação de 6,1 a $8,6 \mathrm{mg} \cdot \mathrm{L}^{-1}$ nos pontos 1 a 10, portanto acima do valor mínimo para a preservação da vida aquática estabelecido pela resolução CONAMA 357/05, que é de 5,0 mg.L.1 (Brasil, 2005). Nos pontos de coleta 11 e 12, próximos à emissão do esgoto doméstico tratado, no entanto, a taxa de variou de 1,3 a 1,6 mg. $\mathrm{L}^{-1}$. Os resultados de Quiñones (2000) indicaram valores entre 0,68 a $4,75 \mathrm{mg} \cdot \mathrm{L}^{-1}$ nos pontos 1 a 10 , muito abaixo dos obtidos nesta pesquisa.

Em 1998, o pH da água variou entre 6,2 e 6,6 (Quiñones, 2000). Encontramos valores de 6,61 a 7,57, com as maiores taxas, como esperado, ocorrendo próximo ao encontro da água doce com a água salgada e tendendo a elevar-se com a influência da maré. Esses dados sugerem aumento na influência marítima, já que o pH da água do mar de Itanhaém, é da ordem de 8,5. O aumento do valor de $\mathrm{pH}$ é outro fator importante a ser monitorado, já que valores elevados contribuem com a proliferação de algas.

A quantificação de coliformes totais e termotolerantes, ou fecais, mais comumente representada pela espécie $E$. coli, é importante para verificar se há interferência antrópica advinda de despejos brutos de esgotos nesses corpos aquáticos. Os resultados das análises microbiológicas estão mostrados na Tabela 6.

Tabela 6. Médias e desvios-padrões das análises microbiológicas das amostras de água coletadas no Estuário de Itanhaém-SP.

\begin{tabular}{cc}
\hline Pontos de coleta & $\begin{array}{c}\text { Contagem de } E \text {. coli } \\
(\mathrm{UFC} / 100 \mathrm{~mL})\end{array}$ \\
\hline 1 & $563,7 \pm 86$ \\
2 & $532,4 \pm 44$ \\
4 & $815,3 \pm 66$ \\
5 & $739,0 \pm 13$ \\
6 & $753,3 \pm 48$ \\
7 & $737,7 \pm 45$ \\
8 & $>10^{6}$ \\
9 & $>10^{6}$ \\
10 & $617,3 \pm 51$ \\
11 & $558,7 \pm 30$ \\
12 & $586,0 \pm 13$ \\
CONAMA & $>10^{6}$ \\
$274 / 00^{*}$ & até $800 \mathrm{UFC} / 100 \mathrm{~mL}$ \\
\hline
\end{tabular}

* parâmetro de águas satisfatórias de acordo com a resolução CONAMA 274/2000 UFC, Unidades formadoras de colônia. Fonte: Autores. 
A maioria das amostras de água estão nos limites de águas próprias satisfatórias (até $800 \mathrm{UFC} / 100 \mathrm{~mL}$ ), de acordo com a resolução CONAMA 274/00 (Brasil, 2000). Porém, as amostras coletadas nos pontos 7 (saída do afluente Ribeirão Campininha), 8 (Ribeirão Campininha) margeados por uma área densamente povoada (Figura 1) indicando o despejo de esgoto doméstico sem tratamento adequado. No entorno pode-se observar presença de tubulações (canos) em residência com despejo de águas próximos aos pontos 7 e 8 (Figura 2). Em relação ao ponto 12, que recebe esgoto da ETE Anchieta, a elevada contagem de E. coli pode ter relação direta com o despejo do efluente doméstico nestas águas.

Figura 2. Registro fotográfico da presença de tubulações provenientes de residências próximas aos pontos 7 e 8 , destacadas em vermelho, indicando o despejo de esgoto doméstico (sem tratamento) nas águas.

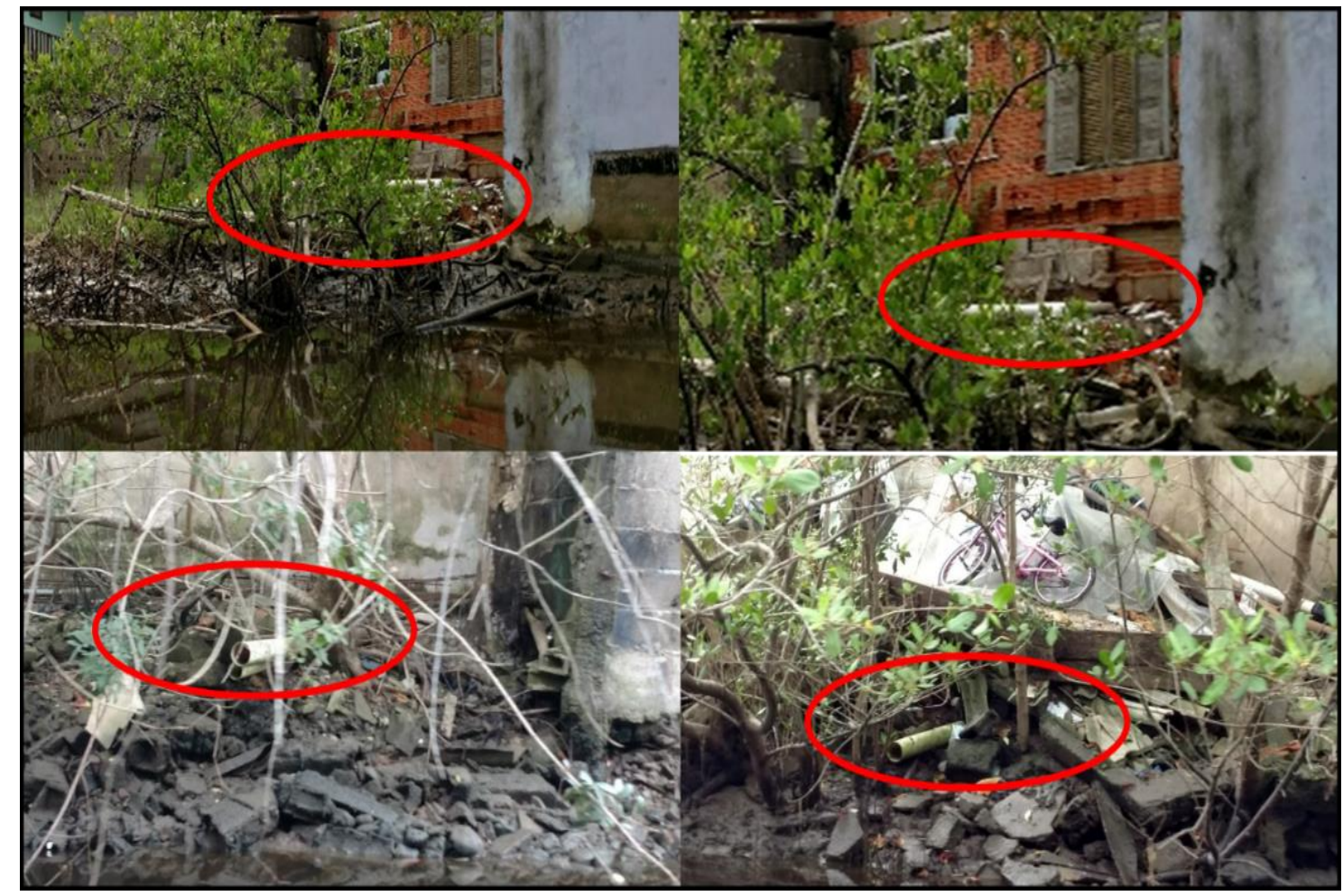

Fonte: Autores.

A observação visual dos locais do presente estudo permitiu inferir que as águas do estuário em questão são utilizadas para várias atividades produtivas da comunidade, como pesca, catação de marisco, recreação de contato primário, navegação, etc. Os ribeirinhos estão em contato constante com a água desse estuário estando sujeitos à contaminação bacteriológica, que tende a diminuir sua qualidade de vida. Além disso, o problema pode causar danos a fauna local desequilibrando o habitat, interferindo principalmente no ciclo das espécies nativas, principalmente de bivalves (predisposição ao parasitismo) (Henriques et al., 2003).

\section{Conclusão}

Os dados sugerem alteração da composição de espécies arbóreas nas parcelas estudadas por Quiñones (2000), especialmente naquelas mais próximas ao Rio Itanhaém e mais estudos são necessários para a efetiva associação desse fato e suas causas.

Em todas as áreas foi constatado aumento de matéria orgânica no solo. O aumento em $91 \%$ na quantidade de plântulas na estação 3 é, aparentemente, resultado do enriquecimento dessa área por substâncias provenientes da ETE, como nitrogênio e 
fósforo, enquanto a diminuição em $23 \%$ no número de plântulas da estação 2 parece estar relacionada ao lançamento de efluentes domésticos in natura pelo Ribeirão Campininha e à grande interferência antrópica no local.

As análises da qualidade das águas nos diferentes pontos de coleta mostraram resultados em desacordo com as Resoluções CONAMA 357/05 e 274/00, com destaque para os pontos 7, 8 e 12 de coleta, com elevada contagem de E. coli, indicando a influência do esgoto doméstico nestas águas. Cabe ressaltar que os pontos 7 e 8 se localizam próximos à estação 2 onde foram observadas alterações na dinâmica da vegetação, com a diminuição do número de plântulas.

Os dados apresentados neste estudo poderão fornecer subsídios para a melhoria das políticas governamentais de monitoramento visando à redução da interferência antrópica na região.

\section{Referências}

Almeida, V. C., Coelho Junior, C., Feitosa, F., Pastor, D., \&Monte, G. (2014). Caracterização estrutural do manguezal do rio Tabatinga, Suape, Pernambuco, Brasil. Tropical Oceanography, 42(1), 33-47.

Alongi, D. M. (2008). Mangrove forests: Resilience, protection from tsunamis, and responses to global climate change. Estuarine Coastal Sciences Association (ECSA), 76(1), 1-13.

Alongi, D. M. (2015). The Impact of Climate Change on Mangrove Forests. Current Climate Change Reports (1), 30-39.

APHA, AWWA, WEF (2017). Standard Methods for the Examination of Water and Wastewater, (23a ed.), Washington, D.C.: American Public Health Association.

Barcelos, M. E. F., Riguete J. R., Silva L. T. P. \& Ferreira Jr., P. F. (2012). Uma visão panorâmica sobre os solos das restingas e seu papel na definição de comunidades vegetais nas planícies costeiras do sudeste do Brasil. Natureza Online 10 (2), 71-76.

Barcellos, D., Queiroz, H. M, Nóbrega, G. N., Oliveira Filho, R. L. de, Santaella, S. T., Otero, X. L. \& Ferreira, T. O. (2019). Phosphorus enriched effluents increase eutrophication risks for mangrove systems in northeastern Brazil. Marine Pollution Bulletin, 142, 58-53.

Bernardino, A. F., Sanders, C.J., Bissoli, L. B., Gomes, L. E., Kauffman, J. B. O., \& Ferreira, T. O. (2020). Land use impacts on benthic bioturbation potential and carbon burial in Brazilian mangrove ecosystems. Limnology and Oceanography, 9999, 1-11.

Blasco, F., Saenger, P., \& Janodet, E (1996). Mangroves as indicators of coastal change. Catena, 27(3-4), 167-178.

Brasil (2000). Ministério do Meio Ambiente. Conselho Nacional do Meio Ambiente. Resolução CONAMA $n^{\circ} 274$ de 29 de novembro de 2000 . Estabelece as condições de balneabilidade das águas brasileiras. http://www.mma.gov.br/port/conama/res/res00/res27400.html.

Brasil (2005). Ministério do Meio Ambiente. Conselho Nacional do Meio Ambiente. Resolução CONAMA $n^{\circ} 357$ de 17 de março de 2005 . Dispõe sobre a classificação dos corpos de água e diretrizes ambientais para o seu enquadramento, bem como estabelece as condições e padrões de lançamento de efluentes, e dá outras providências. http://www2.mma.gov.br/port/conama/legiabre.cfm?codlegi=459.

Brasil (2019). Ministério do Desenvolvimento Regional. Secretaria Nacional de Saneamento - SNS. Sistema Nacional de Informações sobre Saneamento: $24^{\circ}$ Diagnóstico dos Serviços de Água e Esgotos - 2018. Brasília: SNS/MDR, 2019 180p.

Camargo, A. F. M., Ferreira, R. A. R., Schiavetti, A. \& Bini, L. M. (1996). Influence of physiography and human activity on limnological characteristics of lotic ecosystems of the south coast of São Paulo, Brazil. Acta Limnologica Brasiliensia, 8(2), 231-243.

Camargo, A. F. M., Nucci, P. R., Bini, L. M. \& Silva Jr, U. L. (1997). The influence of the geology on the limnological characteristics of some lotic ecosystems of the Itanhaém River Basin, SP-Brazil. Internationale Vereinigung für theoretische und angewandte Limnologie, $26(2), 860-864$.

Casagrande, A. (1948). Classification and Identification of Soils. Transactions of the American Society of Civil Engineers, 113, 901-930. 1948.

CBH-BS (2016). Plano de Bacia Hidrográfica 2016-2027 do Comitê da Bacia Hidrográfica da Baixada Santista. Volume I: Diagnóstico. 456pp

CETESB, ANA. L5.221. (2012). Coliformes termotolerantes - determinação pela técnica de membrana filtrante: método de ensaio. (2a ed.). 18 p. https://cetesb.sp.gov.br/normas-tecnicas-cetesb/normas-tecnicas-vigentes/

Cintrón, G., Lugo, A.E. \& Martinez, R. (1985.) “Structural and functional properties of mangrove forests”, pp. 53-66. In: W.G. D’Arcy, M.D.A. Correa (eds.) The botany and natural history of Panama. Saint Louis, Missouri: Missouri Botanical Garden.

Climate-data.org (2020). Clima: Itanhaém. https://pt.climate-data.org/america-do-sul/brasil/sao-paulo/itanhaem-32844/.

DAEE - Departamento de águas e energia elétrica do Estado de São Paulo. Banco de Dados Hidrológicos (2019). http://www.hidrologia.daee.sp.gov.br/.

De Araújo, R., \& Alfredini, P. (2003). Longshore Sediment Transport Rate Along Suarão and Cibratel Beaches, Itanhaém, SP, Brazil. Journal of Coastal Research, 232-243.

Derísio, J. C. (2013). Introdução ao Controle de Poluição Ambiental. (4a ed.), atual. Oficina de Textos. 
Ellison, J. C. (2014). How South Pacific Mangroves May Respond to Predicted Climate Change and Sea-Level Rise. In: A. Gillespie and W.C.G. Burns (eds.) C. Climate change in the South Pacific: Impacts and Responses in Australia, New Zealand and Small Island States, 289-301. Klewer Academic Publishers, The Netherlands.

Harari, J., \& De Camargo, R. (2003). Numerical simulation of the tidal propagation in the coastal region of Santos (Brazil, 24 S 46 W). Continental Shelf Research, 23(16), 1597-1613.

Henriques, M. B., Marques, H. L. A., Lombardi, J. V., Pereira, O. M. \& Garcia, A. L. B. (2003). Influência da contaminação bacteriológica sobre a resistência do mexilhão Perna perna (L., 1758) à exposição ao ar. Arquivos de Ciência do Mar, 36, 95-99.

Lamberti, A. (1969). Contribuição ao conhecimento da ecologia das plantas dos manguezais de Itanhaém. Boletim da Faculdade de Filosofia, Ciência e Letras da Universidade de São Paulo, 217, série botânica, 23: 1-27.

León, J. A. C. (2005). Calidad de aguas para estudiantes de ciencias ambientales. Universidad Distrital Francisco José de Caldas.

Lopes, D. M. S., Tognella, M. M. P., Falqueto, A. R. \& Soares, M. L. G. (2019). Salinity variation effects on photosynthetic responses of the mangrove species Rhizophora mangle L. growing in natural habitats. Photosynthetica, 57 (4): $1142-1155$.

Lovelock, C. E., Ball M. C., Martin, K. C. \& Feller, I. C. (2009). Nutrient Enrichment Increases Mortality of Mangroves. PLoS ONE 4(5): e5600.

Lugo, A.E. \& Snedaker, S.C. (1974). The ecology of mangroves. Annual Review of Ecology and Systematic, 5: 39-64.

Moschetto, F. A., Ribeiro, R. B., \& De Freitas, D. M. (2020). Urban expansion, regeneration and socioenvironmental vulnerability in a mangrove ecosystem at the southeast coastal of São Paulo, Brazil. Ocean \& Coastal Management, 105418.

Mueller-Dombois, D., Ellenberg, H. (1974). Aims and of vegetation ecology. John Wiley e Sons, 547 p.

Olmos, F.\& SILVA, R. S. (2003) Guará: Ambiente, Flora e Fauna dos Manguezais de Santos-Cubatão, Brasil. Empresa das Artes, 216p.

Pereira, L. A. (2002). Análise ambiental da bacia do Rio Itanhaém baseada na relação entre os aspectos limnológicos com fisiografia, uso da terra e sistema hidrológico -SP. Tese de Doutorado em Geologia Ambiental. Instituto de Geociências e Ciências Exatas, Universidade Estadual Paulista, Rio Claro. 2002.

Piratoba, A. R. A., Ribeiro, H. M. C., Morales, G. P., \& Gonçalves, W. (2017). Caracterização de parâmetros de qualidade da água na área portuária de Barcarena, PA, Brasil. Ambiente \& Água-An Interdisciplinary Journal of Applied Science 12, 435-456.

Quiñones, E. M. (2000). Relações água-solo no sistema ambiental do Estuário de Itanhaém (SP). Tese de Doutorado. Faculdade de Engenharia Agrícola. UNICAMP

Quiñones, E. M., Perez Filho, A. (2001). Influência do esgoto doméstico no ecossistema manguezal. Holos Environment, 1 (2), 199-213.

Ricardi-Branco, F., Branco, F. C., Garcia, R. J. F., Faria, R. S. \& Pereira, S. Y. (2009). Plant accumulations Along the Itanhaém river basin, Southern coast of São Paulo State, Brazil. Palaios, 24(7/8): 416-24.

Schaeffer-Novelli, Y. (coord.) (1995). Manguezal: Ecossistema entre a Terra e o Mar. Caribbean Ecological Research. 64p.

Schaeffer-Novelli, Y., Cintrón-Molero, G., Soares, M. L. G. \& De Rosa, T. (2000). Brazilian mangroves. Aquatic Ecosystem Health and Management, 3 , 561 570 .

Schaeffer-Novelli, Y., Soriano-Sierra, E. J. S, Vale, C.C., do, Bernini, E., Rovai, A. S., Pinheiro, M. A. A., Schmidt, A. J., Almeida, R. de, Coelho Júnior, C., Menghini, R. P., Martinez, D. I, Abuchahla, G. M. de O., Cunha-Lignon, M., Charlier-Sarubo, S., Shirazawa-Freitas, J., \& Cintrón-Molero, G,. (2016). Climate changes in mangrove forests and salt marshes. Brazilian Journal of Oceanography, 64(spe2), 37-52.

Souza-Pereira, P. E., \& Camargo, A. F. M. (2004). Efeito da salinidade e do esgoto orgânico sobre a comunidade zooplanctônica, com ênfase nos copépodes, do estuário do rio Itanhaém, Estado de São Paulo. Acta Scientiarum: Biological Sciences, 26(1), 9-17.

Tam N. F. Y. \& Wong, Y. S. (1996). Retention of Wastewater-Borne Nitrogen and Phosphorus in Mangrove Soils, Environmental Technology, 17(8), 851859.

Von Sperling, M. (2007). Estudos de modelagem da qualidade da água de rios. Belo Horizonte: UFMG, 7. 452 p.

Yang, Q., Tam, N. F. Y., Wong, Y. S., Luan, T. G., Su, W. S., Lan, C. Y., Cheung, S. G. (2008). Potential use of mangroves as constructed wetland for municipal sewage treatment in Futian, Shenzhen, China. Marine Pollution Bulletin, 57(6-12), 735-742. 